\title{
Les agglomérations antiques de Ruessium (Saint- Paulien) et Anicium (Le Puy-en-Velay) et leurs abords
}

\section{Élise Nectoux}

\section{Q OpenEdition}

\section{Journals}

Édition électronique

URL : http://journals.openedition.org/adlfi/6013

ISSN : 2114-0502

Éditeur

Ministère de la culture

Référence électronique

Élise Nectoux, «Les agglomérations antiques de Ruessium (Saint-Paulien) et Anicium (Le Puy-en-

Velay) et leurs abords », ADLFI. Archéologie de la France - Informations [En ligne], Auvergne, mis en ligne le 01 mars 2007, consulté le 19 avril 2019. URL : http://journals.openedition.org/adlfi/6013

Ce document a été généré automatiquement le 19 avril 2019

(C) Ministère de la Culture et de la Communication, CNRS 


\title{
Les agglomérations antiques de Ruessium (Saint-Paulien) et Anicium (Le Puy-en-Velay) et leurs abords
}

\author{
Élise Nectoux
}

\section{Identifiant de l'opération archéologique : 93}

Date de l'opération : 2007 (PT)

La prospection thématique sur les agglomérations antiques de Saint-Paulien et Le Puy-enVelay s'intègre dans le cadre de la thèse en cours Capitales vellaves, topographie urbaine, territoires et paysages, sous la direction de Frédéric Trément, université Blaise-Pascal de Clermont-Ferrand II. La problématique de cette recherche porte sur les dynamiques spatiales et économiques des deux agglomérations pendant l'époque gallo-romaine et a pour but d'apporter un nouvel éclairage sur le transfert de chef-lieu de cité de la fin de l'Antiquité.

2 Cette opération a permis de tester différentes méthodes d'acquisition de données, telles que la prospection pédestre, la prospection aérienne, le relevé de coupes, les sondages et les carottages (paléoenvironnement). La prospection pédestre a permis d'affirmer la présence d'une occupation gallo-romaine sur le site de Marcilhac, habituellement connu pour la période laténienne. La prospection aérienne a permis de mettre au jour plusieurs sites avec des plans partiels de bâtiments, dont certains sont clairement datés d'époque gallo-romaine par le mobilier ramassé au sol. Il s'agit essentiellement de sites environnant Saint-Paulien (Les Ribes) et d'éléments de plan d'habitat pour Ruessium (nord du village actuel de Saint-Paulien). Des éléments de voierie ont également été repérés à Saint Paulien : la voie dite Bolène (traversant l'agglomération) était très nettement visible durant une longue période de l'année (printemps, été), mais également deux tronçons de la voie se dirigeant vers l'est en direction d'Augustonemetum (Clermont-Ferrand). Les 
autres plans de bâtiments peuvent être antiques, mais la datation reste à prouver par la découverte d'éléments mobiliers.

3 Au Puy-en-Velay, un sondage avait pour but de compléter les connaissances sur un quartier en forte restructuration: la place du Clauzel. Le résultat est négatif, mais les données sur le substrat local seront utilisées pour faire avancer un projet de coupe paléotopographique du Mont-Anis, à l'époque gallo-romaine.

4 Un volet d'études paléoenvironnementales a été mis en place et a pour objectif de tenter de préciser la date du transfert de chef-lieu de cité, par le biais d'études palynologiques. La question «dans quel contexte se fait le transfert de chef-lieu? » se transforme en «le transfert de chef-lieu a-t-il un impact sur la végétation, et par ce biais, peut-on préciser sa datation grâce aux études paléoenvironnementales?». Les résultats seront présentés dans le BSR 2008.

5 L'Antiquité tardive, parent pauvre de l'archéologie vellave, voit de nouveaux éléments apparaître à travers les relevés de coupes à l'évêché. Un niveau de retaille de blocs d'arkose est mis en évidence, avec un très fort pendage vers le sud. Il est situé à une altitude inférieure au niveau d'arasement supérieur du mur de soutènement de la terrasse monumentale gallo-romaine ( $\mathrm{II}^{\mathrm{e}} \mathrm{s}$., altitude maximale conservée dans la cathédrale, fouille Sophie Liegard 1992-1995: BSR 1994, p. 54 ; BSR 1995, p. 47-48). La période à laquelle on taille des blocs d'arkose intervient alors que le mur est effondré (stratigraphie) et que la terrasse est en cours de restaurations ou n'est pas encore restaurée. En croisant cette information avec les données anciennes (Aymard Auguste, 1857 - « Origines de la ville du Puy », Bulletin de la société académique du Puy, XXI, p. 217), ce remaniement doit avoir lieu à la fin de l'Antiquité, période à laquelle on retaille des blocs antiques (majoritairement en arkose) pour fonder de nouveaux bâtiments. Rappelons que l'arkose est largement utilisée à la période romaine, mais peu à la période médiévale. À ce même moment, on double le mur de terrasse endommagé, on jette des blocs en partie retaillés entre le premier mur de terrasse et le nouveau et l'on obtient la structure décrite par Auguste Aymard place du For : deux murs en petit appareil, parallèles, entre lesquels on trouve des débris de blocs antiques plus ou moins retaillés. Il semblerait donc qu'une partie de la terrasse se soit effondrée ou ait été détruite lors de la construction d'un édifice, ou peu avant. Une datation absolue manque à ce raisonnement, qui s'appuie sur les jeux de stratigraphie en chronologie relative. Il doit donc rester une hypothèse de travail, à confirmer par de plus amples observations.

Nectoux Élise 
INDEX

Index géographique : Auvergne, Haute-Loire (43), Saint-Paulien, Aiguilhe, Brives-Charensac, Chadrac, Espaly-Saint-Marcel, Le Puy-en-Velay, Vals-près-Le-Puy

operation Prospection thématique (PRT)

Thèmes : acquisition des données, économie (faits), habitat, impact humain, paléoenvironnement, palynologie, terrasse, voirie

Index chronologique : Empire romain, Moyen Âge

\section{AUTEURS}

\section{ÉLISE NECTOUX}

BEN 